\title{
REALISMO JURÍDICO NORTE-AMERICANO, FATOS SOCIAIS E DECISÕES JUDICIAIS: REPERCUSSÕES NO JUDICIÁRIO BRASILEIRO
}

\author{
NORTH AMERICAN LEGAL REALISM, SOCIAL FACTS AND JUDICIAL \\ DECISIONS: \\ REPERCUSSIONS IN THE BRAZILIAN JUDICIARY
}

\begin{abstract}
Liana Zerbielli Trentin Mallmann Mestre em Direito pela Faculdade Meridional - IMED. Bolsista PROSUP/CAPES.

Membro do Centro Brasileiro de Pesquisa sobre A Teoria da Justiça de Amartya Sen: interfaces com direito, políticas de desenvolvimento e democracia. Advogada lianazerbielli@hotmail.com

Neuro Zambam Pós-Doutor em Filosofia na Universidade do Vale do Rio dos Sinos - UNISINOS. Doutor em Filosofia pela PUCRS. Professor do Programa de Pós-graduação em Direito da Faculdade Meridional - IMED - Mestrado. Professor do Curso de Direito (graduação e especialização) da Faculdade Meridional - IMED de Passo Fundo. Membro do Grupo de Trabalho, Ética e cidadania da ANPOF (Associação Nacional dos Programas de Pós Graduação em Filosofia). Pesquisador da Faculdade Meridional. Coordenador do Grupo de Pesquisa: Multiculturalismo, minorias, espaço público e sustentabilidade. Líder do Grupo de Estudo, Multiculturalismo e pluralismo jurídico. Líder do Centro Brasileiro de Pesquisa sobre a Teoria da Justiça de Amartya Sen: interfaces com direito, políticas de desenvolvimento e democracia. neurojose@hotmail.com; nzambam@imed.edu.br
\end{abstract}

Resumo: O realismo jurídico contribuiu para uma abordagem crítica sobre como os tribunais americanos decidiam os casos judiciais. Seus idealizadores proferiram críticas contundentes ao formalismo jurídico e à aplicação mecânica das leis e defenderam que as decisões judiciais deveriam ser tomadas a partir dos fatos sociais e fossem coerentes com a realidade dos casos. Ademais, para o realismo, os juízes eram os responsáveis por "fazer o direito". O método adotado para o desenvolvimento desta pesquisa é o investigativo bibliográfico a partir de Arnaldo Sampaio Godoy e Daniel Ferreira. Mesmo sabendo que o movimento não foi difundido no Brasil, verifica-se que as decisões judiciais brasileiras carregam consigo traços do realismo, impressões particulares e preocupações com as consequências sociais das decisões. Assim, conclui-se que os entendimentos jurisprudenciais brasileiros estão sendo alternados conforme a rotatividade de julgadores no tribunal, caracterizando, desta forma, traços do realismo jurídico nos julgados brasileiros.

Palavras Chaves: Decisões Judiciais. Fatos sociais. Realismo Jurídico. Oliver Wendell Holmes Jr.

Abstract: Legal realism contributed to a critical approach to how American courts dealt with court cases. Its developers made strong criticisms of legal formalism and the mechanical procedure involved in the application of laws, and argued that judicial decisions should be taken based on social facts, maintaining consistency with the case's realities. Furthermore, by the realism approach, judges were responsible for "doing the law". The bibliographic investigation method from Arnaldo Sampaio Godoy and Daniel Ferreira was applied in this research. Even knowing that the movement was not widespread in Brazil, it is observed that Brazilian judicial decisions carry traces of realism within themselves, and also particular impressions and concerns about the social consequences; thus, it was concluded that the Brazilian jurisprudential understandings are being alternated according to the turnover of court judges, characterizing features of legal realism.

Key Words: Judicial decisions. Social facts. Legal Realism. Oliver Wendell Holmes Jr.

\section{Para citar este artigo}

\section{ABNT NBR 6023:2018}

MALLMANN, Liana Zerbielli Trentin; ZAMBAM, Neuro. Realismo jurídico norte-americano, fatos sociais e decisões judiciais: repercussões no judiciário brasileiro. Prisma Jurídico, São Paulo, v. 19, n. 1, p. 153-173, jan./jun. 2020.

http://doi.org/10.5585/prismaj.v19n1.10897. 


\section{Introdução}

O sistema jurídico norte-americano, a partir das décadas de 1920 a 1930, foi o palco da propagação do realismo jurídico. Esse movimento tinha por objetivo alterar a forma como as sentenças judiciais eram prolatadas, reformulando o modo como os magistrados da época conduziam e articulavam suas decisões. Para tanto, a mais imponente tese do movimento foi a de refutar o formalismo jurídico e a aplicação mecânica de leis e jurisprudências, que eram os principais componentes na resolução das lides judiciais na época.

O realismo jurídico orientava que os julgamentos deveriam ser realizados de acordo com os fatos sociais, ou seja, a partir do caso concreto, e não somente baseado na aplicação dos textos legais. Para o realismo, primeiro o juiz deveria decidir em conformidade com o que se apresentava ao judiciário e, após, para fundamentar a sua decisão, deveria ser aplicado o ordenamento jurídico então vigente. Dessa forma, os julgados seriam mais precisos e eficazes, pois se amoldariam melhor à realidade dos fatos. Por isso, para o realismo, "Direito é aquilo que o juiz diz ser".

O propósito do realismo jurídico é edificar uma Filosofia do Direito por meio de uma visão conceitual de análise dos fatos, contexto e circunstâncias, como também preparar os juristas para o exercício de uma sabedoria prática jurídica. Por se direcionarem à realidade social, as instituições jurídicas deveriam ser realistas quanto às necessidades sociais que careceriam serem supridas, reconhecendo assim, o papel central a ser desenvolvido pelo magistrado na administração e aplicação do direito (MACEDO, 2010, p. 04).

O juiz Oliver Wendel Holmes Jr. foi um dos principais expoentes do realismo jurídico e ficou conhecido como o "prolator de votos vencidos" por adotá-lo em suas decisões, o que na maioria das vezes resultava em sentenças que divergiam do entendimento dos demais magistrados. Holmes desenvolveu a teoria do realismo jurídico inicialmente nos bancos universitários, fomentando o desenvolvimento de novos juristas com a preocupação central voltada aos resultados sociais que as suas decisões acarretariam e não somente preocupados com a aplicação fria da lei.

Indubitavelmente surgiram inúmeras críticas ao movimento, como as proferidas por Pound, que embora reconhecesse a importância do movimento realista, defendia o desenvolvimento de uma jurisprudência sociológica, na qual as decisões judiciais deveriam preocupar-se com o fim social que resultariam. Pound alegava, ainda, que os objetivos traçados pelos realistas eram "desconexos" com as atividades dos magistrados, pois eles não 
possuíam uma técnica ou procedimento adequado para a análise dos fatos concretos outrora colhidos e que assim as decisões judiciais não projetavam um fim social.

O movimento do realismo jurídico norte-americano não foi adotado pelo Judiciário nem mesmo pela doutrina brasileira como um meio de aplicação formal do direito. Contudo, o que se pode evidenciar, mesmo que indiretamente, é a existência de traços realistas nos julgados brasileiros. Assim, buscando investigar a possível presença da teoria americana idealizada por Holmes, esta investigação desenvolve-se a partir do seguinte questionamento: podem ser verificadas influências do realismo jurídico norte-americano nas decisões do Judiciário brasileiro?

Neste contexto, buscando construir uma investigação sólida direcionada à solução da problemática exposta, destacam-se como objetivos específicos: a) analisar o surgimento do realismo jurídico norte-americano; b) investigar as principais características e os pensadores do movimento; c) demonstrar a existência de repercussões do realismo jurídico norteamericano no Judiciário brasileiro. O método adotado para este fim é o investigativobibliográfico a partir de obras de Arnaldo Sampaio de Moraes Godoy e Daniel Ferreira, entre outros comentadores. A categoria central que orienta o estudo é realismo jurídico norteamericano.

Dessa forma, para construir uma linha de investigação, a fim de expor o movimento realista norte-americano a partir das premissas que mais se destacam na doutrina, este artigo se constrói a partir de uma arquitetura de quatro tópicos. No primeiro, são expostos os objetivos e as ideias basilares do realismo jurídico norte-americano. No segundo, destaca-se o principal expoente e precursor do movimento, Oliver Wendell Holmes Jr., enfatizando suas convicções e objetivos em vista da mudança na prolação das decisões judiciais. No terceiro, destacam-se as críticas e contribuições de Roscoe Pound ao movimento. E no quarto tópico, de forma a evidenciar o objetivo proposto inicial desta investigação, são expostos os traços marcantes do realismo jurídico norte-americano no Judiciário brasileiro.

O estudo e a compreensão do realismo jurídico, embora integre um movimento da realidade jurídica norte-americana, é de suma importância, considerando que, de forma voluntária ou não, está repercutindo nas decisões dos tribunais brasileiros. A análise desenvolvida ao longo deste artigo demonstra as influências realistas nas decisões judiciais dos tribunais nacionais, que estão sendo desenvolvidas com maior frequência sob a preponderância das concepções próprias dos julgadores (sejam elas morais, políticas ou econômicas), culminando na inobservância do real modelo jurídico brasileiro. 


\section{Principais referências do realismo jurídico norte-americano}

O realismo jurídico norte-americano foi o responsável por propagar o axioma de que os juízes primeiramente decidiam os casos levados ao tribunal de acordo com os fatos socais e posteriormente arquitetavam os meios para fundamentarem as suas decisões. Desse modo, o movimento foi propagado na comunidade como um sistema por meio do qual os juízes decidem de acordo com o que os fatos sociais refletem em seus ideários e depois se utilizam do ordenamento jurídico para fundamentar sua decisão.

Os juristas adeptos ao movimento do realismo jurídico defendiam que o abandono ao modelo formalista e engessado na prolação das decisões judiciais resultaria em julgados que melhor se amoldariam à realidade das partes envolvidas. E também que os pleitos nelas disputados seriam solucionados de forma mais eficaz, pois as decisões eram tomadas a partir da realidade concreta de cada caso, considerando as concepções individuais dos magistrados. Para Moreira, "o realismo jurídico tem como uma de suas premissas a rejeição ao formalismo jurídico, para seus teóricos o mais fator mais importante está na eficácia da norma, ou seja, sua produção de resultado" (MOREIRA, 2019, p. 193).

De acordo com Godoy (2013, 09), o realismo jurídico desenvolveu-se a partir de professores como Karl Llewellyn, Thurman Arnold e Felix Cohen, que atuavam em Johns Hopkins, Columbia e Yale. O movimento surgiu como uma reação ao formalismo existente tanto no Poder Judiciário americano, por meio de decisões consideradas conservadoras que se respaldavam no direito formal, como também nas universidades, por meio do método de estudo de casos. Eclodiu, ainda, como surgimento acidental na academia jurídica, por meio de uma série de interações acidentais que levaram professores e advogados - especialmente Karl Llewellyn, Roscoe Pound e Jerome Frank - a elaborar estudos sobre as decisões judiciais e críticas ao direito como estava sendo praticado até então. (CESTARI, NOJIRI, 2015 p. 145). O realismo jurídico ganhou forças no período entre guerras, "captou material conceitual no intervencionismo do governo Roosevelt”, o qual era marcado pelo plano, o New Deal, perdendo forças durante os anos da luta contra o perigo vermelho, na década de 1950 (GODOY, 2013, 09).

Nas academias, o movimento do realismo jurídico iniciou por meio do descontentamento referente às decisões da Suprema Corte, as quais, de forma contínua e rotineira, invalidavam regulamentações de ordem estadual e federal em matérias econômicas e contratuais. Assim, após o final da primeira guerra mundial, o movimento se expandiu nos tribunais norte-americanos no combate ao colapso progressista. Nesse contexto, destaca-se: 


\begin{abstract}
A narrativa convencional sobre a história do realismo jurídico conta que foi durante as décadas de 1870 até 1920, durante o auge do formalismo jurídico, que advogados e juízes consideravam o direito de forma autônoma, abrangente, logicamente ordenada e determinada. Nesta época, influenciados pelo método de casos de Christopher Langdell, acreditava-se que os juízes se dedicavam a uma dedução mecânica do corpo de leis e precedentes, visando a produção de uma única resposta correta para cada caso. No entanto, a partir das décadas de 1920 e 1930, com base nas ideias de Oliver Wendell Holmes Jr., Roscoe Pound e Benjamin Cardozo, os realistas buscaram tornar o formalismo jurídico obsoleto, demonstrando que a lei está cheia de lacunas e contradições e que o direito é indeterminado, que há exceções para a maior parte das regras legais, princípios e precedentes, e que todos eles podem levar a resultados opostos. Os realistas argumentaram que os juízes decidem de acordo com suas preferências pessoais e, em seguida, constroem sua argumentação jurídica para justificar o resultado por eles desejado (CAMPILONGO et al., 2017. p. 6).
\end{abstract}

O movimento do realismo jurídico buscava desconstruir uma aplicação da lei que era considerada como falha e sempre concluía as decisões com as mesmas respostas. O realismo buscou demonstrar a existência de mais de uma resposta correta para o mesmo caso, como também a dispensabilidade da aplicação de normas e regras legais preestabelecidas.

Objetivou também modificar toda a forma de prolatar as decisões judiciais, fazendo com que elas fossem mais próximas possíveis da realidade, desconstituindo os preceitos preestabelecidos e a aplicação automática das leis. Nesse sentido, os idealistas do movimento acreditavam que as normas legais e a doutrina não eram capazes por si só de produzir decisões judiciais incontroversas. Eles "sustentaram que a doutrina jurídica normalmente não determina resultados legais sem a influência substancial de elementos não-legais, cuja existência e aplicação são variáveis e manipuláveis" (OSTINI, NOJIRI, 2019. p. 140).

Uma das características marcantes e intrínsecas do realismo é que ele descreve a realidade de acordo com o olhar do cotidiano, estando distante de representações e impressões da sociologia ou de qualquer outra ciência (GODOY, 2013, p. 13). Assim, o realismo objetiva construir decisões judiciais a partir da percepção do juiz sobre os fatos sociais e não a partir de regras e normas preexistentes no ordenamento jurídico.

\footnotetext{
O realismo jurídico é movimento prioritariamente intelectual que ganhou dimensão nos Estados Unidos, nas décadas de 1920 e de 1930. Certo olhar cético problematizava como os juízes decidem os casos e o que as cortes de justiça verdadeiramente fazem. Para o realismo, magistrados decidem de acordo com o que os fatos provocam em seus ideários, e não em função de regras gerais que levariam a resultados particulares. Assim, juízes responderiam muito mais aos fatos (factresponsives) do que às leis (rule-responsives). Vários são os fatores que marcam a atuação dos juízes; e são fatores de fundo consciente e inconsciente (GODOY, 2013. p. 14).
}

Conforme enunciado por Godoy (2013, p. 13), há várias percepções que podem ser destacadas pela presença do naturalismo forense na atuação judicial. Benjamim Cardozo (juiz 
adepto ao realismo jurídico) aduz que "há mais de uma forma de decidir um mesmo caso". E os conceitos legais não produziriam os resultados desejados, mas permitiriam que os juízes tivessem vários resultados para um determinado caso, ficando a seu critério qual aplicar. Já para Jerome Frank, a decisão judicial seria um mecanismo de racionalizar a decisão pessoal do juiz, obtida de outros modos, sem a observação a fatos, normas e princípios jurídicos, mas a aspectos psicológicos do juiz. Dessa forma, o realismo permitia que os juízes, ao prolatarem suas decisões, expressassem suas opiniões pessoais referentes ao caso concreto, resultando em uma forma de melhor resolução dos conflitos levados ao Judiciário, pois tornariam as decisões mais concretas e eficazes. Assim, no realismo jurídico norte-americano, os magistrados não estavam adstritos aos textos legais.

Nesse sentido, a primeira parte do século XX foi marcada pelo realismo jurídico que tinha como principal vertente a "dúvida em relação a sistemas de axiomas e de teoremas, bem como do valor de raciocínios indutivos e dedutivos e da possibilidade de que regras formais pudessem organizar as relações humanas" (GODOY 2013, p. 14). O realismo não acreditava que regras e normas jurídicas previamente estabelecidas fossem resolver de forma satisfatória os pleitos levados aos tribunais e duvidava, portanto, do formalismo convencional que compunha a grande maioria dos julgados da época.

O realismo jurídico desenvolveu uma reforma legal nos tribunais para que as decisões deixassem de seguir um formalismo e sistemas lógicos engessados e que se adaptassem aos cotidianos reais da população. Além das alterações que provocaria nas decisões judiciais, também foi responsável por motivar uma profunda alteração na forma de ver e pensar o direito por parte dos seus operadores - juízes, advogados, professores e universitários. Enfim, o realismo buscava construir uma nova forma de edificar e aplicar o direito aos casos concretos.

O realismo foi introduzido no Judiciário a partir da premissa de que o que determina as decisões judiciais são os fatos, como também uma "reação ao formalismo vigente, o florescimento do pensamento mais pragmático na academia e na prática jurídica, principalmente entre acadêmicos das universidades e de advogados" (CESTARI, NOJIRI, 2015 p. 147).

Três dogmas do direito tradicional norte-americano foram contestados pelo realismo jurídico: a primeira posicionou-se em dúvida de que as regras jurídicas eram escolhidas por representação popular; a segunda "zombou" que a democracia era fortalecida pelo controle constitucional das leis exercido pelo judiciário; e, por fim, foi derrubado "o mito de que os Estados Unidos seriam governados por leis, e não por homens". (GODOY, 2013. p. 15). 
Percebe-se, assim, que o realismo desenvolvia uma hostilização às regras, às normas e aos princípios que compunham os códigos norte-americanos, objetivando evidenciar a ineficiência do sistema adotado composto pelo excesso de formalismo e aplicação mecânica das leis.

A principal característica que pode ser destacada para a diferenciação dos realistas aos demais teóricos do direito é a atitude dos magistrados no momento de decidir. Segundo o realismo, a atitude dos juízes realistas é reagir primeiramente aos fatos, ou seja, eles decidem de acordo com o que acreditam ser a melhor escolha conforme os fatos do caso e não necessariamente com a lei que poderia ser aplicada. Enquanto que, para o formalismo jurídico, os juízes devem responder primeiramente aos estímulos e às regras de direito, ou seja, as leis e matérias legais fornecem aos juízes razões constitucionais para aplicar determinada lei. (CAMPILONGO et al., 2017, p. 07). Portanto, enquanto o realismo concentra-se primordialmente nos fatos sociais, o formalismo prioriza a aplicação dos textos legais.

O realismo desacreditava no uso da lógica nas decisões judiciais, uma vez quer era irrefutável que os julgadores primeiro decidiam e após aplicavam os textos legais, ou nas palavras de Godoy (2013. p. 16), ao fundamentar os juízes preocupavam-se em ornamentar suas decisões "com rudimentos de silogismos, premissas, maiores e menores, conclusões, promovendo uma lógica abelardiana macarrônica que se sustenta com a ignorância dos administrados e com a cumplicidade dos iniciados". Assim, o realismo fazia fortes críticas sobre o uso do instrumentalismo, como também da constante ocorrência do afastamento entre os fatos socais e as regras aplicadas.

Nesse contexto, há duas teorias que sistematizam como os juízes respondiam aos fatos sociais: uma é a "teoria idiossincrática, baseada em Jerome Frank, que centra-se no juiz como indivíduo"; outra é a "teoria sociológica, fundamentada em Karl Llewellyn, que centra-se prioritariamente na apreensão e na determinação dos fatos sociais”. Os realistas adotam a teoria idiossincrática, que substancializou a ideia de que "o direito é o que o juiz diz que ele seja. E nada mais". Além disso, para a teoria idiossincrática, a decisão judicial seria o resultado e o reflexo da personalidade do juiz frente a um determinado fato social (GODOY, 2013. p. 20).

O combate à aplicação de jurisprudência mecânica é um dos objetivos do realismo, que compreende que "o principal dever de um magistrado não é declarar a lei, mas manter a paz decidindo as controvérsias levadas a juízo”. (GODOY, 2013. p. 22). Por essa razão, o realismo adota a teoria idiossincrática, na qual compreende que direito é aquilo que o juiz diz 
e não o que está escrito. Para a teoria idiossincrática, na prolação de uma sentença, os fatos e as consequências sociais devem possuir maior "peso" e são fatores que devem guiar o magistrado, e não os textos legais ou a jurisprudência, que não possui o condão de amoldar-se a cada caso em particular.

O realismo apresenta-se como um "movimento" que iniciou nas academias diante da indignação frente a alguns julgados dos tribunais em matérias de economia e contratos, objetivando que as decisões passassem a ser prolatadas a partir da maior observância dos fatos sociais do que da aplicação mecânica de regras e princípios preestabelecidos, haja vista que tal ação não resultaria em decisões que solucionassem de forma eficaz os pleitos levados a juízo. O movimento teve como precursor o jurista Oliver Holmes, que iniciou a disseminação das ideias realistas na Corte americana, sendo de início fortemente contrariado pelos demais magistrados.

\section{0 realismo jurídico em Oliver Wendel Holmes Jr.}

Oliver Wendell Holmes Jr. lutou pela abolição da escravidão e serviu o Exército durante três anos. Conforme tradição familiar, frequentou Harvard, graduou-se em direito e dedicou-se ao exercício da advocacia, como também lecionou por um curto espaço de tempo em Harvard. Publicou vários ensaios jurídicos, artigos, livros, galgando maior reconhecimento com The Commow Law (1881), que apresentou contundentes críticas ao formalismo e ao método do ensino jurídico inserido em Harvard por Christopher Columbus Langdell. Já em 1883, foi nomeado juiz da Suprema Corte Judicial de Massachusetts (NETO, WEDY, 2016, p. 92).

Precursor do movimento do realismo, Holmes levou o pragmatismo ao limite durante os 30 anos (1902 a 1932) que atuou como juiz da Suprema Corte, discordando frequentemente das decisões formalistas de seus colegas, marcando o século XX com grandes mudanças na jurisprudência norte-americana (GODOY, 2013. p. 57).

Holmes enfatizava a influência que os fatos sociais/externos exercem sobre as decisões dos tribunais. Era considerado por muitos juristas como o herói do direito americano, como Benjamin Cardozo, que "o reputava de senhor de todo o direito e da filosofia do direito, o mais perfeito jurista de seu tempo" (GODOY, 2013. p. 60). Felix Frankfurter teria dito que "Holmes era o filósofo que se tornou rei", em decorrência da sua majestosa atuação como juiz e como impulsionador do realismo jurídico. Segundo Godoy (2013. p. 60), Holmes era 
brilhante, trabalhava duro, redigia seus votos com espantosa velocidade, além de ser considerado o primeiro juiz a ter status de celebridade.

A trajetória jurídica filosófica de Holmes é dividida em três fases. A primeira refere-se a sua atuação como advogado, o que ocorreu por um curto período, pois ele teria se desencantado pela profissão. A segunda fase foi marcada pela pesquisa e elaboração de seus dois livros, The Common Law e The Path of the Law. Nessas obras, assim como já mencionado, Holmes critica veementemente o formalismo jurídico, afirmando que a decisão judicial não é a mera aplicação de um precedente, embora insinuasse que um bom juiz inconscientemente julgava de acordo com os padrões médios da sociedade em que vivia. E também defendia que o direito não é lógica, mas experiência, disseminando a metáfora do bad man, do bandido (GODOY, 2013. p. 61).

A metáfora do bad man refere-se à teoria da predição, segundo a qual, na interpretação do Direito, os juristas deveriam focar na previsão de como os tribunais decidirão. Assim, destaca-se:

\begin{abstract}
O que é o Direito? Vocês encontrarão autores que dirão que é algo diverso do que é decidido por tribunais de Massachusetts ou da Inglaterra, que é um sistema racional, que é uma dedução a partir de princípios éticos ou de axiomas consolidados, que pode ou não coincidir com o que foi decidido por aqueles tribunais. Mas se nós pegarmos o ponto de vista do nosso amigo, o homem mau (bad man), nós perceberemos que ele não dá a mínima para princípios ou axiomas ou deduções. $\mathrm{O}$ que ele quer saber é como as cortes de Massachusetts ou da Inglaterra realmente decidirão seu caso. E eu concordo com essa visão. Profecias sobre o que as cortes efetivamente farão, e nada mais pretensioso do que isso, é o que entendo por Direito (HOLMES, 1987).
\end{abstract}

Holmes buscou esclarecer com a metáfora do bad man, as reais preocupações e anseios que possui um suposto bandido quando processado. Para Holmes, este (bandido) preocupa-se somente com as consequências processuais a que estaria sujeito e não com as consequências morais, ou seja, o suposto bandido não dispõe de preocupações morais, apenas se preocupa de que forma será processado e julgado. Por essa razão é que Holmes afirmava que conhecer o direito é saber como os juízes decidirão determinados casos.

A última fase da carreira jurídica de Holmes é o exercício da magistratura nas cortes supremas, em Massachusetts, e depois em Washington. Holmes foi considerado um brilhante juiz, conhecido como o prolator de votos vencidos, por seus votos discordarem constantemente daqueles dos seus colegas. Era reconhecido por redigir seus votos de forma clara, simples e objetiva. Pode-se afirmar que 
[...] os votos dissidentes de Holmes concederam prestígio e popularidade às opiniões vencidas da Suprema Corte, possibilitando a concepção atual dos votos dissidentes como importantes métodos da expressão judicial. Suas decisões judiciais são caracterizadas não apenas pelo emprego de metáforas como instrumento estilístico distintivo, mas também pela brevidade, inovação e franqueza da linguagem empregada, pela insistência em ser específico e não formalista, em identificar valores e políticas ao invés de invocar fórmulas [...] Holmes acreditava que os juízes precisam transcender suas próprias convicções. Sustentava que suas opiniões políticas não interferiam no desempenho de seu papel enquanto membro da Suprema Corte. Conscientemente ele resistiu à pressão dos partidos políticos e da opinião pública, concentrando-se mais no desenvolvimento das estruturas fundamentais do Direito (NETO e WEDY, 2016, p. 20-21).

Nesse contexto, Holmes imprimia em suas decisões seus pensamentos realistas, enfatizando a necessidade de observação dos fatos externos à construção de decisões corretas e eficazes, além da máxima realista de que o direito não se refere às normas e aos princípios positivados, mas que é aquilo que um juiz decide. Ou seja, o direito é aquilo que os juízes dizem que deve ser. Seus votos eram redigidos de forma simples e precisos, imprimindo críticas às aplicações mecânicas das leis e da jurisprudência, defendendo a ideia de que os magistrados deveriam reproduzir em suas decisões as suas próprias convicções e não estar atrelados a leis previamente estabelecidas.

Holmes insistia na flexibilidade da interpretação constitucional. Para ele, a “constituição não é necessariamente um ser vivo e mutante; no entanto, gerações presentes não são prisioneiras do passado. Soluções pretéritas não são necessariamente as mais adequadas para os dias em que vivemos" (GODOY, 203, p. 66). Holmes também desconfiava do tradicionalismo como mecanismo para justificar a autoridade e foi responsável por desenvolver o princípio exegético relativo às “questões de liberdade de expressão, garantindoa, de modo relativo, na medida em que critério de perigo claro e eminente deveria ser o único a orientar o intérprete". Nas questões trabalhistas, posicionava-se ao lado do trabalhador e era reconhecido também por rejeitar o jargão dos especialistas, escrevendo do modo menos formal possível (GODOY, 2013. p. 65).

Holmes foi o criador das frases mais famosas do linguajar jurídico norte-americano. A sua mais eloquente contribuição é que "proposições gerais não decidem casos concretos". (GODOY, 203, p. 67). Assim, destaca-se seu entendimento:

A vida do direito não tem sido lógica: tem sido experiência. As necessidades sentidas em todas as épocas, as teorias morais e políticas que prevalecem, as intuições das políticas públicas, claras ou inconscientes, e até mesmo os preconceitos com os quais os juízes julgam, têm importância muito maior do que silogismos na determinação das regras pelas quais os homens devem ser governados. O direito incorpora a história do desenvolvimento de uma nação através dos séculos e não pode ser tratado como se compreendesse tão somente axiomas e corolários de livros de matemática. De modo a se saber o que é o direito, deve se saber o que ele tem sido e qual a tendência que há de se transformar. Deve se consultar alternativamente a história e as teorias jurídicas existentes (GODOY, 203, p. 67). 
Holmes ressalta sua crítica ao formalismo e à aplicação de leis, normas e jurisprudências mecânicas que não representariam soluções adequadas e eficazes aos pleitos judiciais. Buscava por meio de novas concepções de aplicação do direito que as decisões judiciais fossem prolatadas de forma mais justas e precisas e que os fatos sociais e externos fossem primeiramente analisados e melhor interpretados para a aplicação de uma correta decisão.

Ele deixou importantes legados ao judiciário norte-americano, contudo o mais imponente refere-se a sua afirmação de que o papel dos tribunais é o de ser um dos principais definidores do direito: "as profecias do que os tribunais farão de fato, e nada mais pretensioso, são o que eu considero como lei", do livro "The Path of the Law" - O Caminho da Lei (HOLMES, 1987, p. 461).

Indubitavelmente, Holmes foi uma das figuras mais importantes do realismo jurídico norte-americano, que impulsionou e encorajou outros juízes a prolatarem suas decisões de formas diferentes, abandonando a aplicação da lógica e a jurisprudência mecânica para a construção de decisões que fossem baseadas nos fatos sociais dos casos levados a juízo.

\section{As críticas ao realismo jurídico de Roscoe Pound}

Pound cursou direito em Havard e "reputava a prática do direito como fonte de muito tédio, porém apreciava a filosofia jurídica”. Assim, tomou os caminhos das academias e começou a lecionar direito romano na Universidade de Nebraska; posteriormente lecionou em "Nortwestern Law School, foi contratado pela Universidade de Chicago, e em seguida foi lecionar em Harvard, cuja faculdade de direito dirigiu de 1916 a 1936. Pound lecionou em Harvard até 1964, ano de sua morte" (GODOY, 2013 p. 81).

Pound foi um contemporâneo e uma influência para o realismo jurídico norteamericano, como também desenvolveu duras críticas a este movimento que surgia e se disseminava nas academias. Enquanto diretor de Havard, as críticas ao realismo foram introduzidas por meio da publicação de seu artigo "The call for a Realist Jurisprudence" (Convocação para um Direito Realista), na revista Harvard Law Review.

Salienta-se que o referido artigo teve origem após Karl Llewellyn publicar um ensaio, o qual foi considerado o "batismo" do realismo jurídico. Fala-se em batismo porque este artigo (de Karl Llewellyn) foi apenas a constatação fática da crítica ao formalismo jurídico de Langdel, que já vinha ocorrendo por meio de Oliver Wendell Holmes Jr. e Banjamin Cardozo. De acordo com Ferreira (2012, p. 104), o artigo de Llewellyn foi apenas a "ocasião perfeita" 
para a exteriorização de suas críticas e não a única causa do escrito de Pound, até porque sua crítica está amparada na afirmação de que o movimento "foca na sua faceta da teoria do direito apenas tangenciando a faceta do ensino jurídico ao criticar a insistência dos realistas na aplicação da pesquisa empírica ao direito" (FERREIRA, 2012, p. 104).

Pound, no artigo "The call for a Realist Jurisprudence", reconhece a importância do movimento na comunidade acadêmica americana, uma vez que ganha forças nas universidades, sendo adotado pelos mais novos operadores do direito. Ao analisar a metodologia realista, divide o seu texto em três partes e realiza a análise metodológica de forma distinta em cada uma delas. Assim, a primeira parte do escrito analisa o programa realista de forma geral, sendo a crítica mais contundente que Pound faz ao movimento. Conforme Ferreira (2012, p. 105),

\footnotetext{
Pound definira o que seria realismo para o novo movimento, ele o critica por acreditar que este não teria qualquer finalidade útil. Afirmava que a observação das atualidades da ordem jurídica era importante, mas que não encontrava no movimento realista leia-se, no artigo de Llewellyn, qualquer indicação do que seria feito após tal observação. Ao menos nada que já não houvesse sido realizado anteriormente.
}

Nesse contexto, salienta-se que Pound tinha consciência de que eram necessárias as “observações jurídicas” dos magistrados sob os casos fáticos levados ao Judiciário, contudo enfatizava que os juristas (realistas) não tinham um programa ou uma técnica adequada para desenvolver correta e eficazmente uma análise sobre os dados outrora colhidos. Além disso, de acordo com Ferreira (2012, p. 106), Pound mencionava que essa tentativa dos realistas não era inovadora, pois já havia sido realizada por racionalistas, juristas históricos, juristas analíticos e positivistas, embora os realistas rechaçassem as escolas supramencionadas.

Para Pound, as atividades críticas desenvolvidas pelos realistas eram importantes, principalmente para observação do comportamento dos juízes e dos elementos da atividade judicial que impediriam a uniformidade e a segurança jurídica das decisões. No entanto, afirmava também que elas não poderiam ser usadas como base para o desenvolvimento de uma ciência do direito na sua integralidade, pois uma ciência do direito não poderia basear-se apenas na descrição aperfeiçoada das realidades. Dessa forma, para Pound, a crítica realista ao direito da época seria insuficiente, defendendo assim a sua geração, que era anterior à realista, afirmando que tanto a sua geração quanto a de Llewellyn falham em descrever o direito na sua integralidade. A primeira parte do escrito encerra-se com a crítica à insistência dos realistas "na coleta objetiva e científica de fatos, ou seja, critica a insistência realista na pesquisa empírica, bem como as teorias realistas que utilizavam a psicologia para analisar o 
comportamento individual do magistrado em casos judiciais particulares". (FERREIRA, 2012, p. 106-107).

A segunda parte do artigo está marcada, de acordo com Ferreira (2012, p. 107), por cinco tópicos que sempre apareceriam nos escritos dos realistas:

\begin{abstract}
Um dos pontos mais comuns é a crença em pesquisas empíricas de dados como tendo significado intrínseco e extrínseco [...]; (b) crença em um significado único ou na realidade de algum método ou linha de pesquisa [...] ciência jurídica análoga a física matemática [...]; (c) uma pressuposição de que a análise psicológica seria o unum necessarium [...]; (d) Outra característica é a insistência na análise de apenas um caso em detrimento de uma análise do curso uniforme do comportamento judicial [...]. Neo-realistas radicais parecem negar que existam princípios, regras, conceitos, ou doutrinas em geral [...]; (e) Por fim, muitos dos novos juristas realistas tratam o direito como um corpo de aparatos com objetivo exclusivamente comercial ao invés de enxergarem o direito como um corpo de significados direcionados a fins sociais.
\end{abstract}

Dessa forma, Pound constrói sua crítica a partir de estudos e análises direcionados aos juízes, em como determinados fatos podem ser interpretados e posteriormente solucionados pelos juízes. Ou seja, que os operadores do direito, especialmente advogados, buscam por meio das análises dos magistrados os seus ganhos de causa e não necessariamente um fim social adequado e justo à questão que foi levada ao Judiciário.

E, na última parte de seu artigo, Pound sugere a construção de um programa realista relativo, por meio do qual seria capaz de suprir suas críticas e adequar-se aos padrões traçados pelos autores realistas:

1) uma atitude funcional, isto é, o estudo não só dos preceitos e das doutrinas do direito, porém, e principalmente, um estudo de como o direito efetivamente funciona; 2) o reconhecimento de elementos irracionais, ilógicos e subjetivos nas instâncias reais do direito, isto é, no modo como o direito efetivamente é aplicado; 3) o reconhecimento de circunstâncias únicas e individualizadas, em oposição ao universalismo conceitual do século XVIII; 4) o abandono da ideia de que há uma sequência necessária de acontecimentos, que parte de uma causa única e que caminha para um único resultado possível, no sentido de se admitir que exista apenas uma única solução soberana para um determinado caso levado à justiça; 5) a leitura do direito a partir da psicologia, sem que necessariamente se aderisse a alguma escola específica do pensamento psicológico; 6) a adoção de axiologia que levasse em conta o jogo de interesses a partir da psicologia e da filosofia, sem que, mais uma vez, se aderisse a qualquer dogma dominante nos campos psicológico e filosófico e, 7) o reconhecimento de que há muitas abordagens e possibilidades para se chegar a uma verdade jurídica, sendo que todas elas são significativas em relação aos vários problemas aos quais se referem (GODOY, 2013, p. 84).

A crítica de Pound encerra-se por meio da defesa da existência de uma pluralidade de teorias do direito. Segundo Godoy (2013, p. 84-85), esse relativismo jurídico defendido por Pound é o ponto central do realismo, uma vez que Pound admitia a importância e a contribuição de todas as tendências da filosofia jurídica. 
Pound foi o precursor da jurisprudência sociológica, a qual representa uma extensão do pensamento do jurista Wendell Holmes Jr., que rechaçava o formalismo jurídico, responsável também pela apreensão da diferença “entre o direito que há nos livros e o direito que se desdobra na vida real". Nesse sentido, Pound procurava destacar as discrepâncias existentes entre as "regras que abstratamente normatizam as relações e as normas que efetivamente governam os homens". Ele ilustrava tal afirmativa trazendo à baila o exemplo do controle de constitucionalidade que o Judiciário exercia sobre as leis; entendia que a Suprema Corte norte-americana parecia não considerá-lo um dogma absoluto e mencionava que as cortes declaram inconstitucionais as leis, as quais não aprovam (GODOY, 2013 p. 81).

Pound fazia duras críticas aos juristas que ainda estavam apegados a um direito e jurisprudências antigas, pois, segundo ele, o direito que os livros e textos legais contêm não é o mesmo da vida real. E fazia reiterados apontamentos da necessidade dos juristas aplicadores e estudiosos do direito conhecerem também economia e sociologia, uma vez que o direito não seria autossuficiente para emanar as respostas necessárias às soluções das controvérsias levadas ao Judiciário, necessitando, portanto, de outros conhecimentos para preencher as lacunas deixadas pelo direito.

Pound desenvolveu, a partir do trabalho de Holmes, uma jurisprudência sociológica que se refere a um novo estado de desenvolvimento de teorias jurídicas, a qual, em geral, diz respeito a um estudo da lei que leva em conta os fatos sociais em que está envolvida a lei aplicável. Nesse sentido, Pound desenvolveu seis pontos pragmáticos: 1) O estudo dos efeitos sociais do direito; 2) Direcionar os efeitos do direito com finalidade de preparação e adequação dos textos legais; 3) Criar leis e regras jurídicas de maior efetividade; 4) Realizar estudos dos efeitos sociais do direito em âmbito histórico; 5) Contribuir para uma aplicação justa e equitativa do direito; 6) A promoção do propósito mais importante do direito (DEFLEM, 2006, p. 109).

É nesse sentido que a jurisprudência sociológica é enfática quanto ao real trabalho do direito, que não está ancorado somente na doutrina legal nem mesmo na teoria jurídica. Essa distinção entre o direito que há nos livros e o direito da vida real ocorre em virtude da disparidade da lei em relação aos fatos sociais; a jurisprudência sociológica de Pound busca estudar como a lei deve ser adaptada e adequada para solucionar as controvérsias da sociedade (DEFLEM, 2006, p. 109).

De acordo com a jurisprudência sociológica, as decisões judiciais devem observar e preocupar-se com as consequências sociais que produzirão, assim como as condições em que atuam e com quais propósitos de desenvolvimento, social, econômico ou político. A 
jurisprudência sociológica preocupa-se em delimitar como a lei deve amoldar-se diante dos problemas enfrentados pela sociedade. Dessa forma, somente quando atingidas essas preocupações é que a lei culminará em seus objetivos, promovendo o controle social. Por essas razões é que, segundo Godoy (2013, p. 86), Pound criticava a aplicação de uma jurisprudência mecânica que não observava os fatos para os quais se dirigia. Assim, Pound era defensor da produção de uma legislação de forte conteúdo social que atuasse de forma a contrariar as tendências retrógradas utilizadas pelo Judiciário norte-americano. Dessa forma, como ele esteve por muitos anos à frente de uma das mais importantes e respeitadas universidade de direito (Havard), foi responsável por influenciar milhares de operadores do direito com suas concepções de um direito unido às circunstâncias sociais.

Pound seguia o entendimento de Holmes na busca por substituir a aplicação da lógica formalista pelos estudos empíricos e históricos, que acreditava serem fatores corretos para solucionar as lides judiciais. Acreditava também que assuntos como economia, política e sociologia deveriam ser incluídos concomitantemente à aplicação do direito, para que as funções legislativa e jurídica passassem a ser vistas como funções interligadas e que as decisões judiciais fossem estabelecidas de forma mais real e não engessadas.

\section{O realismo jurídico no judiciário brasileiro}

Os ideais do movimento do realismo jurídico pautavam-se exclusivamente na percepção de que os magistrados deveriam atentar-se exclusivamente aos fatos e às consequências sociais para só então se posicionarem a respeito da solução de um caso. Contudo, a preocupação com a realidade das partes envolvidas e consequentemente com os resultados a que ficariam submetidas não são motivo de inquietação exclusivamente dos realistas norte-americano. É o que comprova uma pesquisa realizada pela Associação dos Magistrados Brasileiros, realizada em 2005, que objetivava analisar e identificar os principais pontos observados pelos juízes para a construção de uma decisão. Assim, a pesquisa foi orientada pela seguinte indagação: as decisões judiciais devem orientar-se por parâmetros legais, atentar para suas consequências econômicas e ter compromissos com as consequências sociais? O resultado da pesquisa evidenciou que: $86,5 \%$ dos entrevistados consideram que as decisões judiciais devem ser orientadas preponderantemente por parâmetros legais; $78.5 \%$ afirmam que se deve ter o comprometimento com as consequências sociais produzidas pelas decisões; somente $36,5 \%$ dos magistrados acreditam ser necessário atentar-se às consequências econômicas (SADEK, 2006, p. 47). 
Diante desses resultados, percebe-se que grande parte dos magistrados brasileiros se preocupa com as consequências sociais da sua decisão, tanto para as partes envolvidas no litígio, como para a sociedade. O Anuário de Justiça de 2010 trouxe outra investigação realizada com os magistrados, na qual foram indagados se eles deveriam atentar-se aos fatores sociais, econômicos e de governabilidade antes de prolatarem suas decisões. Foi certificado que $46 \%$ dos magistrados entrevistados dos Tribunais Superiores - STF e STJ - entendem que devem ser considerados os fatores sociais, econômicos e de governabilidade para o sentenciamento de um caso (ANUÁRIO, 2010, p. 8-9).

Segundo Lênio Streck (2014), o Judiciário brasileiro possui traços do realismo jurídico norte-americano. No Brasil, o direito alternativo tinha raízes realistas. Nas práticas judiciárias, não é difícil encontrar uma série de manifestações realistas. Para o autor, o que ocorre no Judiciário brasileiro é uma espécie de realismo jurídico inconsciente na motivação dos juízes nos processos judiciais. Isso acontece porque os juízes são descrentes quanto à capacidade justificadora do sistema jurídico. "O realismo é cético diante das normas, pois a considera puro papel até que se demonstre o contrário. Assim, a vida do direito é 'experiência'. Por isso, direito passa ser aquilo que os juízes dizem que é" (STRECK, 2014, p. 4).

Nesse contexto, o Judiciário brasileiro vem sendo alvo de críticas quanto a julgados que possuem características do movimento do realismo jurídico no Supremo Tribunal Federal. Um exemplo é o julgamento da Ação Penal 470, conhecida também como "ataque da justiça ao mensalão", que foi responsável pela repercussão de inúmeros debates no campo jurídico nacional. As críticas se referem ao fato de que, para o julgamento, "a maioria dos ministros da corte aderiram a uma postura mais conservadora com relação ao Direito Penal, de modo a evidenciar certo retrocesso no que tange à sua jurisprudência criminal e ao modo de interpretar as garantias processuais dos acusados”. (BALIARDO, HAIDAR, 2012).

Segundo os críticos do julgamento da Ação Penal 470, o tribunal, com o objetivo de condenar os réus, mudou seus paradigmas no processo do mensalão. "Levados por irresistível corrente condenatória, afirmam os advogados, os ministros optaram por um retrocesso em que se atropelaram princípios constitucionais construídos ao longo dos últimos anos" (BALIARDO, HAIDAR, 2012). Ou seja, no referido julgamento houve uma desconstrução de um entendimento edificado pelo tribunal durante anos.

A postura adotada pelo Superior Tribunal Federal violou não só seus próprios precedentes, como também deixou de aplicar ao caso (Ação Penal 470) os mesmos critérios observados e aplicados a casos anteriores semelhantes (precedentes). Assim, por uma motivação, ao que parece, íntima, ou talvez ao anseio de se fazer justiça mediante tantos 
escândalos de corrupção que assombram o país, os julgadores foram levados a, efetivamente, proceder um julgamento de exceção, baseados em diretrizes e axiomas que lhes foram mais convenientes para o caso. As características desse julgamento equiparam-se à prática do realismo jurídico quando observada a forma discricionária adotada pelos julgadores de não "seguir" os precedentes já adotados pelo tribunal e de construir um novo julgamento baseado em argumentos que, para o caso e o momento (do país), melhor se ajustaria.

Oliveira (2012) questiona se tal mudança ocorreu porque se está a julgar a referida ação penal, ou porque houve uma reformulação nos quadros pessoais do tribunal. Ademais, enfatiza o autor: "Quero dizer que, de 2004 a 2012, quatro ministros deixaram a corte e outros três ingressaram nela. Muda-se o juiz, altera-se o comportamento decisório, modifica-se o Direito. Holmes estaria certo?" (OLIVEIRA, 2012).

A crítica construída se traduz pela brusca modificação de entendimento quanto à execução e aplicação aos princípios constitucionais que foram construídos com o passar dos anos pelo tribunal. Assim, estaria exarando suas decisões conforme o entendimento dos juízes (ao longo dos anos alteram-se os magistrados), decidindo ora de uma forma, ora de outra. $\mathrm{Ou}$ seja, o Judiciário brasileiro não estaria mais adstrito aos textos legais e precedentes. E os magistrados estariam construindo os julgados a partir da análise individual de cada caso, na medida de aplicar a esse o que melhor se adequa ao momento ou a situação, sem considerar toda a construção normativa e de precedentes que compõem o Judiciário brasileiro.

Com o objetivo de aumentar o campo de análise dos julgados brasileiros, evidenciando a existência de traços realistas, destacam-se alguns julgados sobre o crime de Porte Ilegal de Armas. No ano de 2004, o Pretório Excelso julgou o RHC 81.057/SP, no qual se discutia sobre a configuração do crime de porte ilegal de armas. Na ocasião, divergindo da relatora, a ministra Ellen Gracie, o ministro Sepúlveda Pertence afirmou que, nesses casos deveria prevalecer a tese de que apenas nos casos de comprovada ofensa ao bem jurídico tutelado pela norma penal é que se teria por tipificada a conduta descrita no crime de porte ilegal de arma de fogo e, em caso contrário (não ocorrência de ofensa ao bem público), a conduta seria atípica. O exemplo que se apresenta seria o da arma desmuniciada. No mesmo caso, o ministro Cezar Peluso acompanhou o voto do ministro Pertence, afirmando, ainda, que "não basta que o tipo penal esteja disposto à tutela de um bem jurídico fundamental; é preciso mais, é preciso que a conduta seja idônea a lesar ou pôr em perigo o mesmo bem". No caso, a tese do ministro Sepúlveda acabou por prevalecer. "Ressalte-se, por relevante, que o STJ, já sob a égide do Estatuto do Desarmamento, tem afastado o crime nos casos de porte de munição sem arma ou de arma sem munição" (OLIVEIRA, 2012). 
Em 2004, o STJ adotou o posicionamento de que se um indivíduo fosse abordado portando somente munição ou uma arma de fogo sem munição, caso não estivesse praticando qualquer ato que viesse a ensejar danos ou ofensa ao bem público, não comportaria acusação da prática de crime de porte ilegal de armas.

Em 2012, porém, a $1^{\text {a }}$ Turma do STF teve entendimento diferente no julgamento de um Habeas Corpus. Ao analisar a ausência da danosidade na conduta do réu "que portava arma de fogo desmuniciada, entendeu que, por se tratar de crime de mera conduta, de perigo abstrato a configuração do crime estava comprovada, sendo irrelevante perquirir, nestes casos, sobre a ofensividade real da conduta". No mesmo sentido foi "o julgamento do HC 88.757/DF, da relatoria do ministro Luiz Fux. Assim também julgou o ministro Dias Toffoli no HC 101.994/SP, de sua relatoria" (OLIVEIRA, 2012).

Delineando a mudança de entendimento, em 2012, o tribunal entendeu por reconhecer crime de porte ilegal de armas a um sujeito que portava arma de fogo sem munição, mesmo sem a comprovação de que a conduta do sujeito foi ofensiva ou danosa ao bem público (requisito adotado em 2004). Ou seja, alteraram-se os julgadores e se modificou o entendimento.

Ao compulsar os exemplos, ressalta-se: a divergência que tinha lugar antes (em 2004) "parece simplesmente ter deixado de existir no momento que houve uma troca de parte dos ministros da corte", isto é, as decisões do tribunal dependem dos ministros que a compõem (OLIVEIRA, 2012). Por fim, não se pretende afirmar que as pessoas não possam ter concepções diferentes sobre o mesmo assunto, "todavia, é no mínimo intrigante que, em se tratando de Direito, estejamos a depender de saber o que pensa o julgador a respeito de determinado tema para termos uma ideia mínima do tipo de decisão que teremos". (OLIVEIRA, 2012).

Destaca-se, ainda, mesmo que simbolicamente para justificar o entendimento desta exposição, o posicionamento de Streck, o qual é enfático ao mencionar que, em uma democracia (como no Brasil), as decisões não podem ser frutos da vontade individual ou da ideologia ou, ainda, da subjetividade do julgador. Assim, o autor defende que:

A primeira coisa que se deveria dizer a um juiz, quando ele entra na carreira é: Não julgue conforme o que você acha ou pensa. Julgue conforme o Direito. Julgue a partir de princípios e não de políticas. Aceitar que as decisões são fruto de uma "consciência individual" é retroceder mais de 100 anos. E é antidemocrático. O direito depende de uma estrutura, de uma intersubjetividade, de padrões interpretativos e não da "vontade". Por isso, minha contestação à frase famosa de Holmes! De Holmes para cá, já se passaram mais de 100 anos... Talvez 100 anos de solidão (STRECK, 2012, p. 6). 
A existência de traços realistas nos tribunais brasileiros é duramente criticada pelos juristas, haja vista que a subjetividade do juiz quando da prolação de uma decisão não deve ser considerada; ele apenas deve obedecer a integridade e a coerência do Direito, sob pena de não estar aplicando o direito, e sim criando-o e interpretando-o conforme sua consciência.

\section{Considerações finais}

O principal precursor do realismo jurídico era consistente ao defender que os magistrados deveriam dirimir os conflitos levados até eles a partir dos fatos do caso concreto e da análise das suas consequências sociais. Para isso, precisavam desvencilhar-se das amarras da aplicação da letra fria da lei e da jurisprudência, pois a observação dos fatos externos da lide proporcionaria decisões mais corretas e de maior eficiência. Assim, Holmes defendia a máxima realista de que o direito não se refere às normas e aos princípios positivados, mas que o direito é aquilo que um juiz decide. Ou seja, o direito é aquilo que os juízes dizem que deve ser.

O realismo jurídico preconiza o distanciamento na aplicação do direito das correntes doutrinárias e dos códigos legais. As decisões judiciais devem ser prolatadas a partir da consciência do julgador sobre as consequências e/ou resultados que esta promoverá na sociedade. Dessa forma, o magistrado deverá atentar-se aos fatos ali evidenciados pelas partes, ocupando-se da fundamentação jurídica somente após a tomada da sua decisão.

Mesmo diante do fato de o movimento do realismo jurídico não ter sido difundido no Judiciário brasileiro, assim como os magistrados realistas norte-americanos, os brasileiros também adotam a preocupação com as consequências sociais das decisões judiciais como fatores a serem analisados de forma equitativa para a construção de uma sentença. Eles não se limitam, portanto, apenas aos textos legais, pois se preocupam com os resultados fomentados por suas decisões.

O objetivo deste artigo não foi generalizar a presença de traços do realismo jurídico na atividade jurisdicional brasileira, mas apenas destacar que, mesmo não existindo o realismo no Brasil, algumas decisões são prolatadas de acordo (ou ao menos parcialmente) com o pensamento de Holmes: "o direito é aquilo que o tribunal diz que é”. Ou seja, algumas decisões judiciais brasileiras estão sendo elaboradas sob influências pessoais dos julgadores, acarretando em sentenças divergentes para casos semelhantes.

Desse modo, fica confirmada a hipótese inicialmente formulada: há, de fato, influência do movimento do realismo jurídico norte-americano nas decisões prolatadas pelo Judiciário 
brasileiro (ao menos nas aqui analisadas). Como restou comprovado, os entendimentos jurisprudenciais estão sendo alternados conforme a rotatividade de julgadores no tribunal; muda-se o julgador, altera-se o entendimento. E, assim, torna-se evidente que as decisões possuem grandes influências pessoais dos magistrados, que imprimem em seus julgados o seu entendimento e não necessariamente o que está adstrito na legislação.

Portanto, mesmo o realismo jurídico norte-americano não sendo disseminado nas academias e nos tribunais (de forma legal e explícita) brasileiros, é um assunto que vem gerando calorosos debates frente à presença de suas características nas decisões judiciais brasileiras. E, dessa forma, cada vez mais se faz oportuno e necessário seu estudo e sua compreensão.

\section{Referências}

ANUÁRIO da Justiça 2010. São Paulo: ConJur Editorial, 2010.

BALIARDO, Rafael; HAIDAR, Rodrigo. Para criminalistas, STF aderiu ao direito penal máximo. NOVA DOUTRINA. Conjur. 2012. Disponível em:

https://www.conjur.com.br/2012-set-27/supremo-mudou-julgar-mensalao-ou-mensalaomudou-supremo\#author. Acesso em: $20 \mathrm{dez} 2017$.

CAMPILONGO, Celso Fernandes; GONZAGA, Álvaro de Azevedo; FREIRE, André Luiz (org.). Enciclopédia Jurídica da PUC-SP. Tomo de Teoria Geral e Filosofia do Direito. Editado pela Pontifícia Universidade Católica de São Paulo São Paulo, abril de 2017. Disponível em: https://enciclopediajuridica.pucsp.br/pdfs/decisaojudicial_58e5af9739138.pdf. Acesso em: 04 jul. 2017.

DEFLEM, Mathieu. Jurisprudência Sociológica y Sociología del Derecho (Sociological Jurisprudence and Sociology of Law). Tradução de Andrés Botero Bernal. Revista Opinión Jurídica, Medellin, Colombia, vol. 05, n. 10, p. 109, jul. 2006. Disponível em: http://www.scielo.org.co/pdf/ojum/v5n10/v5n10a06.pdf. Acesso em: 06 jul. 2017.

FERREIRA. Daniel Brantes. Realismo jurídico norte-americano: origem, contribuições e principais autores. Disponível em: https://www.maxwell.vrac.puc-rio.br/18690/18690 6.PDF. Acesso em: 06 jul. 2017.

GODOY, Arnaldo Sampaio de Moraes. Introdução ao realismo jurídico norte-americano. Brasília: Edição do autor, 2013.

HOLMES, Oliver Wendell. The path of the Law. 1897. Disponível em: http://www.gutenberg.org/ebooks/author/4722. Acesso em: 05 jul. 2017.

MACEDO JÚNIOR, Ronaldo Porto. Posner e a Análise Economica do Direito: Da Rigidez Neoclássica ao Pragmatismo Frouxo: Dialógos entre Direito e Economia. São Paulo: Saraiva, 2010, p. 04. 
MOREIRA, Mônica Emília. Realismo jurídico e positivismo jurídico: Uma Conexão Necessária. Direito em Debate: Revista do Departamento de Ciências Jurídicas e Sociais da Unijuí, Ijuí, Ano XXVIII, n. 52, p.184-194, jul./dez. 2019.

NETO, Eugênio Facchini; WEDY, Ana Paula Martini Tremarin. Revista da AJURIS. Sociological jurisprudence e realismo jurídico - a filosofia jurídica norte-americana na primeira metade do século XX. Porto Alegre, v. 43, n. 140, p. 75-123, junho 2016.

OLIVEIRA, Rafael Tomaz. Supremo está entre o legalismo e o realismo jurídico. Diário de Classe. Conjur, 2012. Disponível em: https://www.conjur.com.br/2012-out-20/diario-classesupremo-entre-legalismo-realismo-juridico. Acesso em: $20 \mathrm{dez} .2017$.

OSTINI, Taísa Magro; NOJIRI, Sergio. Neoconstitucionalismo: a reinterpretação da Constituição e o ativismo judicial. XXVIII Encontro Nacional do Conpedi Goiânia - Teorias do Direito, da Decisão e Realismo Jurídico. Florianópolis: CONPEDI, 2019, fls: 135 - 155. Disponível em:

conpedi.danilolr.info/publicacoes/no85g2cd/d72z98si/cRhnGDO12Xw31I2U.pdf Acesso em: 07 mar. 2020.

POUND, Roscoe. The call for a Realist Jurisprudence. In: Harvard Law Review. Vol. 44, $\mathrm{n}^{\circ}$ $5,1931$.

SADEK, Maria Tereza; BANETI, Sidnei Agostinho; FALCÃO, Joaquim. Magistrados: Uma Imagem em Movimento. Rio de Janeiro: Fundação Getúlio Vargas, 2006.

STRECK, Lenio Luiz. O passado, o presente e o futuro do STF em três atos. Senso Incomum. Conjur, 2012. Disponível em: https://www.conjur.com.br/2012-nov-15/senso-incomumpassado-presente-futuro-stf-tres-atos. Acesso em: 12 jan. 2018.

STRECK, Lenio Luiz. O realismo ou quanto tudo pode ser inconstitucional. Senso Incomum. Conjur, 2014. Disponível em: https://www.conjur.com.br/2014-jan-02/sensoincomum-realismo-ou-quando-tudo-inconstitucional\#top. Acesso em: 20 dez. 2017. 